\title{
A vida cotidiana no relato humanizado do perfil jornalístico
}

Amanda Tenório Pontes da Silva*

Resumo: Com a evolução técnica das mídias impressas, acompanhada pela inserção de um pensamento sensível na escrita jornalística, produzir e publicar gêneros que primam pela poética das narrativas tornou-se uma significativa maneira de afirmar o imaginário cultural. Ouvir e escrever os relatos das personagens constitui-se numa arma contra a estagnação elaborativa da concepção vertical de mediador. Nesse contexto, o presente artigo tem a proposta de tentar entender como o perfil pode ser utilizado para discutir, através do seu apelo empático ao passado, a identidade do indivíduo envolto e descrito pela linguagem jornalística, esta que normalmente prima pelo tempo presente.

Palavras-chave: Cotidiano; personagem; perfil jornalístico.

\section{Daily life in the humanized report of the journalistic profile}

\begin{abstract}
With the technical evolution of the printed medias, mediated by the insertion of a sensible thought in written periodistic, to produce and to publish genres that prevail by poetic of the narratives that is a significant way to affirm the cultural imaginary. To hear and to write the histories of the personages is a weapon against elaborative stagnation of the vertical conception of mediator. In this context, the present article has the objective to understand as the profile to be used to discuss, in the empathic appeal of the past, the identity of the individual enveloped and described by the journalistic language, this that normally prevails by the present time.
\end{abstract}

Keywords: Actuality; personage; journalistic profile.
Artigo recebido em: 16 de setembro de 2010 Aprovado em: 2 de outubro de 2010

\section{* Graduada em} Jornalismo e Mestranda em Comunicação, ambos pela Universidade Federal da Paraíba - UFPB. Bolsista Capes. Integrante do Grupo de Pesquisa sobre o Cotidiano e o Jornalismo, vinculado ao PPGC/UFPB.

amanda_tenorio@hotmail.com 


\section{Introdução}

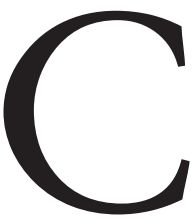

lassificar gêneros e formatos presentes no jornalismo impresso brasileiro deve ser uma atividade contínua dos estudiosos que baseiam suas pesquisas nos numerosos, e em constante transformação, estilos que compõem a linguagem jornalística. Em meio a um numeroso arsenal de exemplos empíricos, a busca pela criatividade através de uma escrita envolvente e humanizada tornou-se dilema para os profissionais que tentam exercer o que cientificamente analisamos observando a prosa diária das mídias.

O perfil é um dos formatos do jornalismo interpretativo (DIAS et al, 1998, p. 13-14), sendo elaborado a partir de uma narrativa que focaliza momentos da vida de um personagem não-ficcional. Podemos dizer que seu auge em termos de periodicidade ocorreu na década de 1960, quando, no Brasil, começou-se a dar destaque às figuras que despontavam em diferentes cenários sociais.

Os feitos que movimentavam a sociedade não eram mais descritos como algo generalizante, os jornalistas buscavam indivíduos que, a partir de trechos da sua história relacionados ao fato, pudessem representar o todo. E aqueles sujeitos que recorriam à notoriedade, encontravam na mídia o lugar perfeito para promoverem a sua existência e capacidade de se auto-afirmar. Os repórteres, aproveitando-se dessa sede de espetáculo, começaram a dar um novo molde ao perfil, mais próximo ao que hoje se lê.

Longe do maniqueísmo imposto ao jornalismo, nosso objetivo não será esvaziar cada ponto referido nesta introdução, mas compreender a relação entre eles. Para isso, lançamos o seguinte questionamento: seria possível retratar o cotidiano através de um formato construído a partir da visão do perfilado sobre si próprio e do autor sobre esta visão?

\section{Contextualizando o jornalismo brasileiro}

Desde o seu início, o jornalismo fornece produtos necessários à solidificação do homem enquanto sujeito moderno. Seguras modificações estimularam o modo de pensar e classificar os gêneros e formatos jornalísticos, onde, apesar das diferenças e similaridades, detectamos uma constante preservada, em uns mais em outros menos: o dever de informar e a necessidade de opinar. Sucintamente explica Marques de Melo (1994, p. 65):

A nota corresponde ao relato de acontecimentos que estão em processo de configuração e por isso é mais frequente no rádio e na televisão. A notícia é um relato integral de um fato que já eclodiu no organismo social. A reportagem é um relato ampliado de um acontecimento que já repercutiu no organismo social e produziu alterações que são percebidas pelas instituições jornalísticas. Por sua vez, a entrevista é um relato que privilegia um ou mais protagonistas do acontecer, possibilitando-os um contato direto com a coletividade. 
Para entendermos como o processo de autoria na atividade oscilou ao longo dos anos, seguindo a história da imprensa, exporemos as etapas citadas por Elcias Lustosa (1996) em "O texto da notícia", que divide o jornalismo no Brasil de 1808 até hoje, em cinco ciclos.

Na primeira fase, que vai até 1827 , as matérias tinham o lado opinativo acentuado por princípios cristãos e morais. A segunda segue até 1889 , com o surgimento das primeiras agências de notícias e a valorização do texto em ordem cronológica.

Inicia-se o terceiro e marcante movimento, que vai até 1930. Neste período, com a proclamação da República, as notícias meramente informativas passam a ser adotadas. Há uma segregação entre os meios de comunicação da época, alguns começam a ser perseguidos, outros fechados, o que causa um aumento da censura. Em contraposição a isso, os jornais ficavam cada vez mais profissionalizados com tecnologia vinda do exterior, possibilitando sua melhoria estética.

De 1930 a 1969, com a Era Vargas, as mídias impressas iniciaram a utilização da técnica do lide, que facilitava a elaboração do texto de forma padronizada. A partir de 1969 prevalece a cultura visual, como a televisão, que passará a moldar jornais e revistas. A partir de 1980 começamos a verificar a informatização das redações e a adoção de técnicas mais apuradas de diagramação.

Analisando essa cronologia, entenderemos o jornalismo como uma disciplina cujo objetivo principal gira em torno da circulação da informação por meio de uma linguagem específi$\mathrm{ca}$ a jornalística, inicialmente regada por pressupostos. Dentre eles, segundo os antigos manuais, destacamos a objetividade, a imparcialidade e a veracidade na descrição dos fatos veiculados.

Nessa seara, contudo, percebemos que nos últimos anos uma

Classificar gêneros e formatos no jornalismo impresso deve ser uma atividade contínua dos estudiosos nova discussão vem se fundamentando em torno da possibilidade de uma escrita humanizada em jornalismo. Grande número de pesquisadores começou a se interessar pela produção de material que tivesse como centro não só o cume da história descrita na notícia. Segundo Vicchiatti (2005, p. 23):

Essa voracidade em informar a qualquer custa, que culmina em julgamentos dolorosos e imprecisos, é, na maioria das vezes, fruto do jornalismo de resultados. $\mathrm{O}$ jornalista não leva em consideração que numa mensagem subliminar pode estar uma preocupação latente de toda uma coletividade.

No caso deste objeto, para entendermos o fenômeno do perfil jornalístico no presente, devemos considerar três pontos muito claros e necessários para desenvolver um material jornalístico envolvente: o primeiro seria a elaboração da narrativa dando foco às personagens, o segundo a construção do texto no perfil que geralmente segue a lógica da entrevista em profundidade margeada por uma forte pauta, e, por último, o que compreendemos como o cotidiano social e as formas apresentadas por ele a serem inseridas no jornal. 


\section{As narrativas e a arte de contar histórias no jornalismo}

O homem como indivíduo particular e a sua relação com a humanidade enquanto elemento universal permanecem sendo bem delineados através das narrativas. Nelas podemos analisar como foram perpetuados os acontecimentos do passado e como os mesmos encontram-se enraizados na cultura e no presente.

Enquanto estrutura, a narrativa jornalística deve conter em seu corpo algumas características fundamentais, destaca-se aqui: exposição, complicação e resolução, podendo, quase sempre, vir acompanhada de uma "moral" a ser passada pelo texto, desenvolvidas pela ação das personagens.

Quanto ao conteúdo, as narrativas naturalmente trazem inúmeras temáticas e naturezas refletidas em seu corpo. Quando veiculadas por meios de comunicação recebem o nome de midiáticas. Neste segmento em especial, trataremos das jornalísticas. Cremilda Medina, fundamental pesquisadora da humanização das práticas jornalísticas, acredita no compromisso das mesmas com a cidadania:

Legibilidade, identificação com anônimos e histórias de vida, rejeição às cargas conceituais e estáticas, e preferência pela informação humanizada, exemplificada na vida cotidiana e pelos heróis da aventura contemporânea, fazem o universo social estar presente dentro dela. (MEDINA, 2002, p.63)

Frutos de uma apurada pesquisa de campo e da sensibilidade do repórter, as histórias devem ser estimuladas e contadas por meio do jornalismo. Com elas podemos escrever como enxergamos a realidade dos sujeitos do mundo, como diz Raul Vargas (1998), construindo a memória dos homens e mulheres que não se conformam em perder a vida, tentando converter o temporário em eterno.

\section{As personagens no centro da narrativa}

A contemporaneidade tem no sujeito o seu fio condutor; o jornalismo tem no personagem o centro do perfil. Através deste formato, sem dúvida, podem ser construídos verdadeiros retratos jornalísticos baseados na vida cotidiana, configurando-se num bom revelador do estilo da época e dos atores que elaboram o conhecimento coletivo.

A origem da palavra personagem advém da raiz comum à etimologia de persona, com significado próximo ao de máscara, ou seja, entidade tomada pelo indivíduo que variará segundo as convenções sociais. Nesse contexto, apontaremos abaixo como a personagem se liga a fatores essenciais do seu convívio para conceber sua visão de mundo. Diante disso, Beth Brait (1987, p. 42-45) indica a classificação feita por Phillipe Hamon:

a) Personagem referencial - é o que se refere a um sentido pleno e fixo. Sua participação e identificação dependerão do reconhecimento do leitor na cultu- 
ra da qual o personagem faz parte. Rotineiramente a imprensa traz histórias de vida de personalidades que as pessoas já conhecem, pois estes estão inseridos na mesma cultura dos leitores;

b) Personagem anáfora - normalmente circunda alguém desconhecido do grande público e só pode ser apreendida dentro do texto;

c) Figurantes - na maioria das vezes ocupam lugares subalternos nas obras. Distanciados e passivos, são pouco significativos no campo psicológico, mas muito importantes no aspecto físico, servindo para ilustrar lugares e dar atmosfera ao ambiente narrado.

Ao citarmos essas colocações seria natural nos perguntarmos em que momento surge a personagem na narrativa. Devemos entender que ela habita a linha tênue onde estão os limites do ser reproduzido e do inventado. E.M. Forster, em Aspects of Novel (apud Brait, 1987, p.41-3), classifica-as de duas maneiras:

a) Personagem plana - construído de forma fixa e em torno de uma única qualidade ou característica, está imune à evolução no transcorrer da narrativa. Normalmente pode ser dividido em tipo e caricatura;

- personagem-tipo - o traço marcante a ser destacado é aquele que deu notoriedade ao indivíduo sem atingir a deformidade;

- personagem-caricatura - muitos sujeitos cometem gestos e atitudes estranhas, tendo tendência à exibição. Não obstante, autores utilizam a deformação e a incoerência para tornar o personagem caricatural;

b) Personagem redonda - apresentado a partir de sua complexidade, normalmente dinâmica e particularizada às idiossinNão se pode datar precisamente quando o perfil começou a ser publicado no jornalismo brasileiro crasias humanas.

$\mathrm{Na}$ verdade, é desejo do jornalismo dar a sensação de realidade às personagens. Notamos que, por esse motivo, a sua caracterização não atenderá apenas aos aspectos psicológicos, mas também aos físicos, contribuindo para a criação de um elo de percepção do leitor. Seja pelas minúcias da altura, peso, expressão facial ou estilo de vestir, cada variação trará consigo parte da história a ser narrada. Segundo Oswaldo Coimbra (2002), demarcamos a personagem também pela:

a) Fala. As descrições expostas para caracterizar um personagem não se limitam apenas ao que for dito pelo autor. As atitudes, assim como o jeito de falar, podem trazer interessante material para a análise da persona a ser construída. A maneira como um personagem se expressa revela, além de fortes características sócio-contextuais, um pouco de sua história;

b) Idade. A mídia é um exemplo de fonte de inúmeras manifestações de linguagens, que irão variar segundo a idade dos envolvidos na comunicação. Revistas adolescentes como "Capricho" e "Atrevida” acentuam as reportagens sobre jovens galãs ídolos de Hollywood, adotando gírias e jargões usados en- 
tre os adolescentes, servindo também como elemento de auto-afirmação do grupo no qual é compreendida;

c) Profissão. Em matérias de jornalismo especializado é notória a forma como profissionais de uma determinada área lidam com o vocabulário próprio de suas profissões. Fala-se, portanto, na dificuldade que é adentrar por essa linguagem;

d) Posição social. A classe de maior prestígio econômico e social tende a utilizar a linguagem culta na sua comunicação, seja escrita ou falada. A gíria e a linguagem descomprometida gramaticamente têm quase sempre ligação com o "popular" ou "coloquial";

e) Região geográfica. Vários fatores podem desencadear a interpretação da origem dos sotaques dos personagens. Um deles é a geográfica, que não tem origem apenas na naturalidade-nacionalidade, mas no lugar onde reside o personagem. Este fenômeno pode desencadear um processo interessante de interação entre os personagens, pois a forma de usar a língua irá variar e será traço marcante na comunicação entre eles.

\section{O perfil jornalístico}

Não se pode datar precisamente quando o perfil começou a ser publicado no jornalismo brasileiro, fala-se em algo em torno dos duzentos e cem anos de existência. No entanto, a partir da década de 1930, influenciado em parte pelas publicações norte-americanas "Esquire", "Vanity Fair", "Life" e "The New Yorker", o formato começou a ganhar destaque nos jornais e nas revistas do país, principalmente aqueles com publicação semanal e mensal.

As revistas que investiram no perfil foram as já extintas "O Cruzeiro" e "Realidade", na última era comum o jornalista acompanhar por semanas a vida da figura a ser perfilada. Das atuais, destacamos "Veja", que, desde 1968 até hoje, de forma não periódica, dá destaque aos indivíduos cuja história normalmente esteja ligada a um fato ou polêmica do cotidiano.

O perfil vem sendo conceituado de diferentes maneiras pelos interessados em seu estudo. Close-up, retratos de vida, reportagem narrativo-descritiva de pessoa e até biografia curta. Muniz Sodré e Maria Helena Ferrari acreditam que exista o perfil, o texto que enfoca o protagonista de uma história (de vida), e o miniperfil, quando uma personagem secundária tem a sua vida narrada a partir de um corte na história principal.

A entrevista tornou-se uma etapa fundamental na elaboração do perfil, pois através dela como instrumento metodológico foi possível angariar o espaço necessário para o jornalista buscar aproximação e narrar densamente o encontro com o seu entrevistado. Segundo Cremilda Medina (1990, p.18): "Ao lidar com o perfil humanizado, consciente ou inconscientemente, se faz presente $o$ imaginário, a subjetividade. Como enquadrar nos limites de um questionário fechado, duma cronologia rígida, de uma presentificação radical uma personagem que ultrapassa estes ditames?".

Seja um anônimo ou conhecido do público, através do perfil é possível encontrar a profundidade que existe na aparência do relatado. Ele tem um estilo único no jornalismo, baseando-se no processo: autor - perfilado - autor - per- 
fil - leitor. Os perfis cumprem um papel importante que é a preocupação com a experiência do outro.

Importante ressaltar os principais atributos do formato, entre os quais, podemos destacar: pleno destaque na pessoa, preocupando-se em desvendar a ideologia das personagens, mesmo que esta retrate apenas o momento presente e tenda a ser modificada com tempo; e eliminação dos pressupostos do jornalismo meramente informativo, diminuindo a negação da subjetividade e o famoso foco no factual.

Ao contrário das biografias, o perfil tem se consagrado por construir narrativas sintéticas sobre trechos da vida de um personagem onde não é importante relembrá-la por completo, mas transcrever apenas algo que a ponha em parâmetro perfilável, com a vivência interpondo ideias e conceitos atuais aos do passado e futuro.

O repórter, no entanto, não deve estar preso à velha obrigação de "cumprir ficha”, mas sim em demonstrar através da sua escrita um jornalismo ético e compromissado. Esclarecemos aqui que não pregamos a exacerbação da subjetividade em lugar da objetividade, mas sim a congratulação da ideia de que cabe aos jornalistas não apenas informar ao público, mas sim instigá-lo dentro da sua própria percepção do real.

\section{O perfil e o cotidiano: em busca das formas sociais}

Os indivíduos e os fatos não podem ser considerados expressões passivas de um espaço individual e isolado, pois são sínteses complexas de elementos sociais (TEDESCO, 2003). Nesse contexto, compreendermos a relação entre o cotidiano e o perfil servirá como base para se perceber cada estágio da vida de uma pessoa como representações de personas distintas, estas que tomam unidade na forma dessa narrativa jornalística e biográfica única.

Didaticamente, na atualidade, o conceito de cotidiano ainda não está completo, mas em plena construção. Não devemos pensar nele apenas como saber do tempo presente, mas na validade da sua ambientação histórica. Para José Machado Pais (2001, p. 72):

A vida quotidiana não se constitui num objeto unificado por qualquer sistema conceptual e teórico corrente e próprio, embora seja um termo que se tem imposto, orientando reivindicações, atitudes, discursos. Por outro lado, o quotidiano é um lugar privilegiado da análise sociológica na medida em que é revelador, por excelência, de determinados processos do funcionamento e da transformação da sociedade e dos conflitos que a atravessam.

Ao longo do tempo, determinadas correntes consideradas tradicionais em disciplinas como História e Sociologia preferiam dar destaque aos feitos que se destacavam ao que era comumente observado na rotina das populações. Com isso, ignorava-se, de certa forma, a importância dos fatos da vida diária. João Carlos Tedesco (2003, p. 23) entende que: 
É importante que tenhamos em mente a relevância para o estudo das ciências humanas, para a análise das ações cotidianas, dos pequenos episódios, dos fatos sans prestige, que constituem, como diz Lefrebvre, a substância do cotidiano. Por mais que pareça óbvio e sem importância não podemos esquecer que a trajetória de nossa vida, do nascimento até a morte, constitui-se numa cotidianidade.

Sucintamente, Pereira (2007), em artigo intitulado "A comunicação e a cultura no cotidiano", divide o cotidiano, para fins metodológicos, em três momentos. O primeiro é o mundo da vida, estabelecido por Alfred Schutz em sua fenomenologia; o segundo é o conceito de cotidianidade, no qual a qualidade da vida e a organização do tempo consomem grande parte das discussões sobre a importância das rotinas. Por último, o mais recente postulado, a vida cotidiana.

Um grande expoente nos estudos sobre o modo de vida das sociedades "efêmeras" tem sido o sociólogo francês Michel Maffesoli, cuja teoria que ajuda a fundamentar, nomeada de formismo, acentua as riquezas existentes nas situações que, a priori, não demonstram a sua potencialidade. Seu olhar traduz as intencionalidades dos sujeitos pós-modernos e como socializam em busca de grupos onde possam se compreender. Para Maffesoli (apud Tedesco, p.124):

O cotidiano é uma forma (anti-racionalizada) teatralizada e superficial, cujo estudo demanda compreender o jogo das formas sociais aí presentes. As formas nas quais os fenômenos sociais aparecem e se enquadram dão a simbologia e a significação do mundo fenomênico; são a matéria-prima de como o mundo se dá a conhecer.

Como a grande preocupação vem sendo entender as formas sociais na interação dos indivíduos em torno das mídias, valorizando as suas histórias pessoais e visões de mundo construídas a partir dos encontros, o perfil aparenta ser um formato jornalístico adequado para entendermos a sensibilidade presente na vida cotidiana sem fugir da proposta e do estilo do jornalismo. Segundo Maffesoli (2007, p. 31):

A noção de formismo não permite mais contra-sensos habitualmente induzidos pela ideia de forma; essa me parece bastante adequada para descrever, de dentro, os contornos, os limites e a necessidade das situações e das representações constitutivas da vida cotidiana.

Apesar de ocupar um espaço geralmente curto se comparado aos outros formatos jornalísticos, o perfil cumpre um importante papel mesmo que em anos ou meses depois o entrevistado tenha mudado de opinião. O que importa, na verdade, assim como no cotidiano, é o momento, o instante. Ou seja, como ele lê a sua vida a partir do atual. 


\section{Considerações finais}

Com este artigo constatamos que a narrativa jornalística, através do seu vínculo espaço-temporal, tem um estilo textual que facilita a leitura e contribui para a construção do jornalismo enquanto saber compromissado com o imaginário presente na cultura das sociedades.

Buscamos acentuar a riqueza do perfil, que lida diretamente com episódios selecionados da história das personagens, cujas trajetórias são narradas criativamente pela linguagem deste formato específico que tem papel importante na estruturação do jornalismo impresso brasileiro, mesmo que atualmente conte com escasso apoio dos veículos de comunicação, o que quantitativamente não significa dizer baixa qualidade do material publicado.

Enfadados de lermos notícias e reportagens, que somam grande parte dos textos dos jornais diários, sobre intrigas, invasão de privacidade e episódios plantados com as consideradas celebridades, tudo em busca de obter uma possível intimidade necessária ao leitor, há de se estimular a captação da sensibilidade do sujeito por trás do mito, as sutilezas do encontro e a observação atuante do repórter.

Concluímos, dessa forma, que o jornalista não pode ser apenas um mediador de conflitos, nem um indivíduo centralizado no passado, mas necessita perceber os detalhes da vida diária para dar a sua opinião a respeito das diversas situações que o leitor não pode vivenciar, cumprindo, ainda assim, os pressupostos condizentes com a rotina da profissão.

\section{Referências bibliográficas}

BRAIT, Beth. A personagem. São Paulo: Ática, 1987.

COIMBRA, Oswaldo. O texto da reportagem impressa. Um curso sobre sua estrutura. São Paulo: Ática, 2002.

DIAS, Paulo da Rocha et al. Gêneros e formatos na comunicação massiva periodística: um estudo do jornal "Folha de São Paulo" e da Revista "Veja”. In: Congresso Brasileiro de Ciências da Comunicação, 21., 1998, Recife. Anais... São Paulo: Intercom, 1998, p. 1-23.

LUSTOSA, Elcias. O texto da notícia. Brasília: UnB, 1996.

MAFFESOLI, Michel. O conhecimento comum: introdução à sociologia compreensiva. Porto Alegre: Sulina, 2007.

MARTINEZ, Mônica. Jornada do herói: a estrutura narrativa mítica na construção de histórias de vida em jornalismo. São Paulo: AnnaBlume, 2008. MEDINA, Cremilda. Entrevista: o diálogo possível. São Paulo: Ática, 1990. . Entrevista: um diálogo possível. São Paulo: Ática, 2002.

MELO, José M. A opinião do jornalismo brasileiro. Petrópolis: Vozes, 1994.

PAIS, José Machado. Vida cotidiana: enigmas e revelações. São Paulo: Cortez Editora, 2001.

PEREIRA, Wellington J. O. A comunicação e a cultura no cotidiano. Porto Alegre: Revista FAMECOS, 2007, quadrimestral, n. 32, abr. 2007. Disponível em: http://revistaseletronicas.pucrs.br/ojs/index.php/revistafamecos/article/ 
viewFile/3416/2679. Acesso em: 07 mai. 2010.

SODRÉ, Muniz; FERRARI, Maria Helena. Técnica de reportagem: notas sobre a narrativa jornalística. São Paulo: Summus, 1986.

TEDESCO, João Carlos. Paradigmas do cotidiano: Introdução à constituição de um campo de análise social. Passo Fundo: UPF, 2003.

VARGAS, Raul H. A reportagem literária no limiar do século 21: o ato de reportar, os jovens narradores e o projeto São Paulo de Perfil. São Paulo: Universidade de São Paulo/ ECA, Dissertação de Mestrado, 1998.

VICCHIATTI, C. A. . Jornalismo: comunicação, literatura e compromisso social. São Paulo: Paulus Editora, 2005.

VILAS BOAS, Sergio. Biografias \& Biógrafos: Jornalismo sobre personagens. São Paulo, Summus: 2002. , Sergio. Perfil: e como escrevê-los. São Paulo: Summus, 2003. 